\title{
A LEI 12.873/2013, AS ESTRUTURAS FAMILIARES MODERNAS E O PRINCÍPIO DA IGUALDADE: ANÁLISE DAS NOVAS REGRAS DE CONCESSÃO DO SALÁRIO-MATERNIDADE EM RELAÇÃO ÃS FAMÍLIAS MONOPARENTAIS
}

\author{
THE LAW 12.873/2013, THE MODERN FAMILY STRUCTURES AND THE \\ PRINCIPLE OF EQUALITY: ANALYSIS OF THE NEW MATERNITY PAY'S \\ RULES FOR GRANTING IN RELATION TO THE ONE-PARENT FAMILIES
}

\author{
${ }^{1}$ Caroline Schneider \\ ${ }^{2}$ Ellen Carina Mattias Sartori
}

\section{RESUMO}

O salário-maternidade é um instituto previdenciário de vital importância, tanto para a criança, que chega à nova família, quanto para a mãe, que recebe amparo financeiro enquanto afastada de sua atividade laborativa, assim como para o Estado, que mantém o seu elemento constitutivo povo em constante renovação. O presente artigo busca fazer uma análise desse benefício, desde sua origem, até as recentes inovações feitas pela lei para o acolhimento de diversas formas de famílias. O artigo procura tratar, pontualmente, da nova figura do salário- maternidade e da sua concessão em caso de falecimento do recebedor preeminente, com o consequente recebimento pelo cônjuge ou companheiro sobrevivente. Em seguida, o estudo tece críticas a essa ampliação legislativa, feita de forma tão restritiva, sem analisar a realidade fática das novas estruturas familiares, dando-se ênfase à questão da família monoparental. Desse modo, o artigo procura frisar que não há embasamento constitucional e legal para a não interpretação com fulcro no princípio da igualdade, amparando, consequentemente, as famílias monoparentais e qualquer parente que fique responsável pelos primeiros cuidados com a criança.

Palavras-chave: Salário-maternidade, Falecimento do segurado, Novas estruturas familiares, Ampliação, Família monoparental, Princípio da igualdade

\begin{abstract}
The maternity pay is an important social security institute, both for children that arrive in a new family and for the mother, which receives financial support while she is away from her labor activity, as well as for the State, which keeps its constitutive element "people" in constant renewal. The present article seeks to make an analysis of this benefit since its very beginning, until the latest innovations made by law for the reception of different forms of family. The article searches to treat, punctually, of the new figure of maternity pay and its grant in case of preeminent receiver's death, and consequently receipt by the surviving spouse or partner. Then, the study criticizes up this legislative expansion, made so narrowly, without analyzing the factual reality of new family structures, emphasizing the question of the one- parent families. Thereby, the article pursuit to point that there is no constitutional or legal basis for refuse a interpretation based on the principle of equality, supporting, consequently, the one-parent families and any relative who be responsible for the very first cares with the child.
\end{abstract}

Keywords: Maternity pay, Insured's death, New family structures, Expansion, Oneparent family, Principle of equality

\footnotetext{
${ }^{1}$ Mestranda do Programa de Pós-Graduação em Direito pela Instituição Toledo de Ensino de Bauru/SP - ITE, São Paulo (Brasil). Coordenadora da Escola Superior de Advocacia do Núcleo da Subseção de Ourinhos/SP, São Paulo (Brasil). E-mail: krolschneider@hotmail.com

${ }^{2}$ Mestre em Sistema Constitucional de Garantia de Direitos pelo Instituição Toledo de Ensino - ITE, São Paulo (Brasil). Professora do Instituição Toledo de Ensino - ITE, São Paulo (Brasil). E-mail: ecsartori@uol.com.br
} 


\section{INTRODUÇÃO}

Não há dúvida da importância dos primeiros dias de convívio entre a mulher e seu filho. Os laços iniciais entre a mãe e seu filho, seja biológico ou adotivo, são fundamentais para o desenvolvimento saudável da criança, e isso não passou despercebido para o Estado.

O Estado não se imiscuiu da obrigação de amparar a mulher garantindo-lhe esse direito social fundamental, permitindo o cuidado com os filhos e, concomitantemente, a sua proteção no mercado de trabalho, tanto em relação à manutenção do emprego quanto em relação à perquirição de renda durante os primeiros cuidados com o filho. Esse amparo à mulher-mãe é feito tanto pelo Direito Previdenciário, como pelo Direito Trabalhista, estabelecendo a Constituição Federal de 1988 , em seu artigo $6^{\circ}$, caput, ser um direito social a proteção à maternidade.

O Direito Previdenciário garante à mulher-mãe o salário-maternidade com duração média de 120 dias, permitindo uma prorrogação estabelecida em lei. É justamente esse direito que o presente artigo pretende analisar, muito embora não exaustivamente.

Já em relação às regras trabalhistas, cinco são as concessões permitidas pela ordem jurídica pátria: a) a estabilidade no emprego, desde a confirmação da gravidez até cinco meses após o parto, nos moldes do artigo 10 do Ato de Disposições Constitucionais Transitórias (ADCT); b) a licença-maternidade de 120 dias, nos moldes do artigo $7^{\circ}$, inciso XVIII da Constituição Federal; c) a mudança de local de trabalho ou de função, de acordo com prescrições médicas, como medida protetiva do desenvolvimento gestacional, além da permissão para a saída, em horário de trabalho, para a realização de exames e consultas, nos parâmetros estabelecidos pelo artigo 392, $\S 4^{\circ}$ da Consolidação das Leis do Trabalho (CLT); d) a autorização, de acordo com o artigo 394 da CLT, para rescisão do contrato de trabalho quando prejudicial à gestação, sem a aplicação de qualquer desconto ou indenização; e) e por fim, a caracterização de ilícito penal de qualquer conduta discriminatória do empregador em relação ao estado gravídico ou quanto à fertilidade da empregada, nos critérios definidos pela Lei 9.029/1995.

Voltando à análise previdenciária, tema central desse trabalho, hoje, no entanto, não podemos mais apenas tratar da mulher-mãe como beneficiária do salário-maternidade. As mudanças na ordem social e, portanto, familiar, conduzem à releitura do instituto. Nas relações homoafetivas, o benefício passa a ser concedido a homens adotantes, coadunando com as novas 
formações familiares baseadas no amor e, a partir de 2013, no caso de morte da gestante, o benefício previdenciário passa a ser concedido ao pai da criança,

desde que respeitado os requisitos legais. Essa nova hipótese de concessão do saláriomaternidade, ao pai ou companheiro viúvo, que será a aqui analisada.

O desenvolvimento do artigo, assim, partirá da análise do instituto do saláriomaternidade, desde sua implantação no sistema jurídico pátrio até a edição da Lei 12.873/2013. Numa segunda toada, o artigo analisará a inserção da Lei 12.873/2013 na ordem jurídica e seus requisitos concessivos, como uma forma evolutiva da legislação previdenciária. Num terceiro momento, o artigo analisará as novas estruturas familiares, dando ênfase à família monoparental, pela ótica da Constituição Federal de 1988, em compasso com o princípio constitucional da igualdade.

Sob esse prisma, o artigo buscará conclusões quanto à evolução do benefício previdenciário, analisando se houve evolução da legislação previdenciária. Analisar-se-á, inclusive, se, de acordo com parâmetros constitucionais, poderia a legislação já ter evoluído mais.

No aspecto metodológico, será utilizado o método de orientação de conhecimento dedutivo, pois, partindo-se das premissas apresentadas referentes ao salário-maternidade, às transformações sociais e às novas estruturas familiares, chega-se à conclusão do trabalho. Quanto à natureza e ao objetivo, trata-se de uma pesquisa teórica, exploratória e explicativa, que busca o aprofundamento do conhecimento sobre o tema, analisando-se desde a inserção no ordenamento pátrio do instituto do salário-maternidade até a vigência da Lei 12.873/2013. Em relação à fonte de dados, pesquisa é bibliográfica, sendo utilizada a documentação indireta, empregando-se obras doutrinárias presentes em livros, artigos em periódicos impressos e no meio eletrônico.

\section{A EVOLUÇÃO DO DIREITO AO SALÁRIO-MATERNIDADE}

O primeiro diploma normativo a tratar da mulher empregada em estado gravídico foi o Decreto no 21.417-A de 1932 (BRASIL, 1932), pelo qual o Governo Provisório regulou as condições de trabalho da mulher no comércio e na indústria. Estabelecia a norma que a mulher gestante tinha o direito de ficar afastada por quatro semanas antes, e até quatro semanas depois do parto, sendo vedado por lei seu trabalho nesse período (artigo $7^{\circ}$ ), e garantido o direito de reverter ao lugar que ocupava. Durante o período de afastamento do trabalho, recebia 
um auxílio no valor de metade de seu salário, feito pela média dos últimos seis meses de remuneração. A responsabilidade pelo pagamento era das Caixas criadas pelo Instituto do Seguro Social, e na falta destas, pelo empregador.

Na sequência, as Constituições de 1934 (BRASIL, 1934) e de 1937 (BRASIL, 1937) tratavam sobre a assistência à gestante, assegurando-lhe um período de repouso antes e depois do parto. A Constituição de 1934, inclusive, estabelecia que o descanso não prejudicaria nem o salário e nem o emprego, instituindo, também, que a lei promoveria a instituição de previdência a favor da maternidade.

A Consolidação das Leis do Trabalho (BRASIL, 1943), em 1942, ampliou o período de duração do repouso da gestante, proibindo o exercício do trabalho pelo prazo de seis semanas antes e seis semanas depois do parto, em seu artigo 392. Observa-se que esse prazo foi aumentado ao longo dos anos, culminando, em 2002, com a estipulação da licençamaternidade pelo prazo de 120 dias, a contar do $28^{\circ}$ dia antes do parto ou da data deste.

Em seguida, o artigo 393 da CLT, determinava, em sua redação original, que durante o repouso a mulher teria direito aos salários integrais, sendo-lhe assegurado o direito de reverter à função que anteriormente ocupava.

As Constituições de 1946 (BRASIL, 1946) e de 1967 (BRASIL, 1967) continuaram no mesmo caminho de proteção, assegurando o repouso da gestante, sem prejuízo do emprego e nem do salário. Inclusive, tratavam da previdência social contributiva em favor da maternidade.

Em 1974, com a Lei 6.136/1974 (BRASIL, 1974), o salário-maternidade é instituído com a natureza jurídica de benefício previdenciário, passando a responsabilidade de seu pagamento à Previdência Social (mais especificamente ao Instituto Nacional de Previdência Social - INPS, hoje denominado Instituto Nacional do Seguro Social (INSS), que foi criado em 27 de junho de 1990, durante a gestão do então Presidente Fernando Collor de Melo, por meio do Decreto $\mathrm{n}^{\circ}$ 99.350, a partir da fusão do Instituto de Administração Financeira da Previdência e Assistência Social (IAPAS) com o Instituto Nacional de Previdência Social (INPS)).

Com a Lei n. 6.136, de 7.11.74, o salário-maternidade passou a ser pago como prestação previdenciária, desonerando-se o empregador de pagar o salário da empregada gestante no período em que lhe era garantido o afastamento do serviço, na época, de doze semanas. Desde então, a empresa adiantava o salário integral à empregada em gozo de licença-maternidade e depois era reembolsada desse valor quando dos recolhimentos devidos ao INSS (CASTRO; LAZZARI, 2014, p. 766).

Embora o empregador pagasse o salário da funcionária como se trabalhando estivesse, posteriormente os valores eram reembolsados pela Previdência Social, em relação a 
recolhimentos previdenciários futuros. Esta forma de ressarcimento é utilizada até hoje, cabendo ao empregador o pagamento do salário da funcionária afastada, com a compensação desses valores em futuros recolhimentos à Receita Federal.

No que toca à Constituição Federal de 1988 (BRASIL, 1988) estabelece o artigo $7^{\circ}$, inciso XVIII, que:

Art. 7. São direitos dos trabalhadores urbanos e rurais, além de outros que visem à melhoria de sua condição social:

XVIII - licença à gestante, sem prejuízo do emprego e do salário, com a duração de cento e vinte dias;

Em seguida estabelece o artigo 201, II da Carta Magna vigente:

Art. 201. A previdência social será organizada sob a forma de regime geral, de caráter contributivo e de filiação obrigatória, observados critérios que preservem o equilíbrio financeiro e atuarial, e atenderá, nos termos da lei, a:

$[\ldots]$

II - proteção à maternidade, especialmente à gestante;

A Lei 8.213/1991 (BRASIL, 1991), em seu artigo 71, determinou que o saláriomaternidade fosse concedido à segurada empregada, à trabalhadora avulsa e à empregada doméstica. Com a Lei 8.861/1994 (BRASIL, 1994), passou o benefício a ser concedido para as seguradas especiais, desde que comprovado um tempo mínimo de exercício de atividade rural, conforme estabelecido em Lei. Na sequência, a Lei 9.876/1999 (BRASIL, 1999), mediante o cumprimento da carência do recolhimento de dez contribuições mensais, concedeo à contribuinte facultativa e à contribuinte individual.

Portanto, a partir de 1999, a gestante que contribui para o INSS - salvo a segurada especial, que mesmo sem contribuição tem direito a percepção do salário, se comprovar os requisitos legais -, passa a ter direito ao salário-maternidade.

Observa-se que, para a segurada empregada, para a trabalhadora avulsa e para a doméstica, a concessão do benefício independe do cumprimento de carência mínima.

O salário-maternidade tem duração de 120 dias, podendo ser concedido 28 dias antes da data do parto, mediante atestado médico, ou da data deste.

Em 2002, o salário-maternidade recebe sua primeira alteração pela modificação social da concepção da expressão "mãe", pois passa a englobar a concessão à mãe adotante. Tal direito ao benefício existe ainda que a mãe biológica tenha recebido o salário-maternidade quando do nascimento da criança.

\footnotetext{
A licença da mãe adotante adveio da proteção constitucional da família e de todos os entes que a compõem, equiparando o filho biológico ao filho adotivo, com o objetivo de propiciar o amparo social e preservar a dignidade da pessoa humana, respeitando o determinado no art. 227, $\$ 6^{\circ}$, da Carta Magna. (EDUARDO; EDUARDO, 2013, p. 364)
} 
De início, no entanto, o período de recebimento era escalonado de acordo com a idade da criança adotada, variando de 120 dias, quando a criança possuía até 01 ano de idade, a apenas 30 dias, se a criança possuísse de 04 a 08 anos de idade. Em 2013, tal diferenciação, que afrontava veementemente o princípio da isonomia, foi reparada pela Lei 12.873 (BRASIL, 2013), que passou a conceder o benefício do salário-maternidade para a mãe adotante pelo prazo de 120 dias, independente da idade da criança adotada, tudo conforme estipulado no artigo 71-A, da Lei 8.213/1991. No entanto, salienta-se que, por ordem judicial emanada em uma Ação Civil Pública proveniente do Estado de Santa Catarina, o INSS já vinha aplicando o prazo para todas as seguradas adotantes, independente da idade da criança adotada.

Segundo o relatório de conversão da Medida Provisória 619, de 06 de junho de 2013 (BRASIL, 2013), que culminou na Lei 12.873/2013, o prazo para a duração do saláriomaternidade foi estendido para que o benefício ficasse com prazo coerente à licençamaternidade já alterada na CLT, pela Lei 12.010/2009.

15. Propõe-se ainda a alteração da redação do art. 71-A da Lei n. ${ }^{\circ} 8.213$, de 1991, a fim de que seja assegurado o salário-maternidade, pelo período de 120 (cento e vinte) dias, à segurada da Previdência Social que adotar ou obtiver guarda judicial para fins de adoção de criança, independentemente da idade. Sabe-se que o art. 392A da Consolidação das Leis do Trabalho, com a redação alterada pela Lei ${ }^{\circ} 12.010$, de 3 de agosto de 2009, ampliou o período de licença da segurada empregada, sem restrição de idade da criança, mas não houve a mesma ampliação no que se refere ao benefício previdenciário. Dessa forma, a medida ora proposta se coaduna com a proteção à infância e com a necessidade de convívio mais intenso entre adotante e adotado, evitando, assim, qualquer discriminação no mercado de trabalho da mulher, na medida em que a despesa da empresa com a sua remuneração no período será custeada pelo Regime Geral de Previdência Social.

16. Cumpre esclarecer, finalmente, que tal alteração vem ao encontro da sentença proferida na Ação Civil Pública no 5019632-23.2011.404.7200, em 03 de maio de 2012, pelo Juízo Federal da $1^{\text {a }}$ Vara Federal de Florianópolis/SC, que já vem sendo plenamente cumprida, por parte do Instituto Nacional do Seguro Social - INSS, em todo o território nacional, de forma que a proposta em tela atende o contido no art. 195, §5º, da Constituição Federal, havendo correspondente fonte de custeio. (BRASIL, 2013)

Observa-se que, nos moldes do Estatuto da Criança e do Adolescente (ECA) e da Instrução Normativa (IN) 77 de 2015 do Instituto Nacional do Seguro Social (INSS) (BRASIL, 2015), em seu artigo 344, apenas no caso de adoção de criança com até 12 anos incompletos o benefício se faz de direito.

Há que deixar ressaltado que, embora a lei tenha pacificado a situação em relação à adoção de crianças, não o fez quanto à adoção de adolescentes, ponto que foi enfrentado pela Ação Civil Pública de Santa Catarina, que ordenou ao INSS conceder o salário-maternidade 
pelo prazo de 120 dias para a segurada que adotar ou obter a guarda judicial para fins de adoção de criança ou adolescente, independente da idade.

Avanço importantíssimo da Lei $12.873 / 2013$ foi a permissão para a concessão do salário-maternidade para o segurado do sexo masculino, em caso de adoção ou guarda judicial para fins de adoção. A possibilidade de concessão está positivada no caput do artigo 71-A, da Lei 8.213/1991.

O ordenamento jurídico não pode fechar os olhos para as relações homoafetivas e a possibilidade desses casais adotarem crianças. A concessão do benefício do salário- maternidade para o segurado que irá fazer a adaptação da criança no novo lar coaduna com a dignidade da pessoa humana e a busca da felicidade pelo indivíduo, hoje valor defendido pelo Supremo Tribunal Federal:

\footnotetext{
Parece-me irrecusável, desse modo, considerado o objetivo fundamental da República de "promover o bem de todos, sem preconceitos de origem, raça, sexo, cor, idade e quaisquer outras formas de discriminação" (CF, art. $3^{\circ}$, IV), que o reconhecimento do direito à busca da felicidade, enquanto ideia-força que emana, diretamente, do postulado constitucional da dignidade da pessoa humana, autoriza, presente o contexto em exame, o rompimento dos obstáculos que impedem a pretendida qualificação da união civil homossexual como entidade familiar.

É preciso também não desconhecer, na abordagem jurisdicional do tema ora em exame, a existência dos Princípios de Yogyakarta, notadamente daqueles que reconhecem o direito de constituir família, independentemente de orientação sexual ou de identidade de gênero (BRASIL, 2011).
}

A Lei 12.873/2013, nessa mesma linha progressista, ainda trouxe uma nova forma de concessão do salário-maternidade, quando do falecimento da segurada ou do segurado que inicialmente iria receber o salário-maternidade, passando a fazer jus ao benefício o cônjuge ou companheiro sobrevivente, que irá cuidar da criança. Tal previsão está no artigo 71-B da Lei $8.213 / 1991$, e é o tema central do referido trabalho, passando seus aspectos a serem analisados em seguida.

Frisa-se, portanto, que a Lei 12.873/2013 equiparou a duração do saláriomaternidade da segurada adotante ao da mãe biológica, legalizou o salário-maternidade para a adoção por casais homossexuais e ampliou o benefício quando da morte de quem inicialmente receberia o salário para o recebimento pelo cônjuge ou companheiro sobrevivente. Não há como não aceitar a evolução do referido instituto. 


\title{
2. A LEI 12.873/2013 E A CONCESSÃO DO SALÁRIO-MATERNIDADE AO CÔNJUGE OU COMPANHEIRO SOBREVIVENTE
}

Embora as mudanças aqui analisadas tenham entrado definitivamente no ordenamento jurídico com a Lei 12.873 de outubro de 2013, tudo se iniciou com a Medida Provisória 619 de junho de 2013, que deve ter sua história legislativa analisada para o bom entendimento evolutivo do instituto. A Medida Provisória na sua edição, quando entrou no mundo jurídico, apenas tratava da hipótese da equiparação entre a mãe biológica e a mãe adotante, o que inseriu pela Lei

12.873/2013 o artigo 71-A na Lei 8.213/1991.

Na sequência, quando da conversão da Medida Provisória em Lei, em relação ao salário-maternidade, ela recebeu duas emendas, as de números 60 e 61, que, segundo o relatório da conversão dispõe:

\begin{abstract}
As emendas $n^{\circ} 60$ e 61 pretendem assegurar o salário-maternidade e a licençamaternidade, respectivamente, ao empregado homem que adote ou obtenha guarda de criança, na ausência de mulher com que realize conjuntamente tais atos. Entendemos meritória essa proposta, pois o intuito da licença e do saláriomaternidade é assegurar o convívio da criança com quem lhe criará. Na ausência da mãe, é imprescindível que o pai se dedique integralmente à criança por seis meses, para assegurar o vínculo afetivo necessário. (BRASIL, 2013)
\end{abstract}

Com a publicação da Lei 12.873/2013, o artigo 71-A da Lei 8.213/1991 passou a dizer respeito ao segurado e a segurada adotante, alcançando os homens de forma expressa. Hoje, apesar de a questão da adoção por casais homossexuais ainda estar envolta em controvérsias (GAGLIANO, PAMPLONA FILHO, 2014, p. 525), entende-se que não há mais qualquer tipo de impedimento legal quanto à possibilidade de adoção por casais em união homoafetivas.

Durante as discussões para a conversão da Medida Provisória, outro dispositivo, que não constava inicialmente no diploma legal, foi inserido na lei de conversão, estabelecendo o novo artigo 71-B da Lei 8.213/1991 que:

Art. 71-B. No caso de falecimento da segurada ou segurado que fizer jus ao recebimento do salário-maternidade, o benefício será pago, por todo o período ou pelo tempo restante a que teria direito, ao cônjuge ou companheiro sobrevivente que tenha a qualidade de segurado, exceto no caso do falecimento do filho ou de seu abandono, observadas as normas aplicáveis ao salário-maternidade. (Incluído pela Lei $n^{\circ} 12.873$, de 2013).

$\S 1$ o O pagamento do benefício de que trata o caput deverá ser requerido até o último dia do prazo previsto para o término do salário-maternidade originário. (Incluído pela Lei $\mathrm{n}^{\circ} 12.873$, de 2013)

$\S 20$ O benefício de que trata o caput será pago diretamente pela Previdência Social durante o período entre a data do óbito e o último dia do término do saláriomaternidade originário e será calculado sobre: (Incluído pela Lei no 12.873, de 2013) I 
- a remuneração integral, para o empregado e trabalhador avulso; (Incluído pela Lei $\mathrm{n}^{\mathrm{o}} 12.873$, de 2013)

II - o último salário-de-contribuição, para o empregado doméstico; (Incluído pela Lei $\mathrm{n}^{\circ} 12.873$, de 2013)

III - 1/12 (um doze avos) da soma dos 12 (doze) últimos salários de contribuição, apurados em um período não superior a 15 (quinze) meses, para o contribuinte individual, facultativo e desempregado; e (Incluído pela Lei $\mathrm{n}^{\circ} 12.873$, de 2013)

IV - o valor do salário mínimo, para o segurado especial. (Incluído pela Lei $\mathrm{n}^{\mathrm{o}}$ 12.873, de 2013)

§ 3o Aplica-se o disposto neste artigo ao segurado que adotar ou obtiver guarda judicial para fins de adoção. (Incluído pela Lei n ${ }^{\circ} 12.873$, de 2013)

Para a concessão do salário-maternidade, na forma do artigo 71-B, quando do falecimento da segurada ou segurado, o cônjuge ou companheiro sobrevivente deverá ficar com o filho, não fazendo jus ao benefício na hipótese de falecimento da criança ou se abandoná-la, inclusive não fará jus se houver a perda ou destituição do poder familiar por ordem judicial.

Será, no entanto, analisada a situação previdenciária do sobrevivente para a concessão, devendo ele possuir qualidade de segurado e a carência mínima necessária para a concessão do benefício, de acordo com sua categoria contributiva.

Ao contrário do salário-maternidade da parturiente, que pode ser requerido dentro do prazo de cinco anos do fato gerador do benefício, o salário-maternidade requerido pelo sobrevivente deve ser requerido no prazo de 120 dias do fato gerador do benefício. Tal prazo coaduna com a finalidade da concessão, que é de ter o cuidador em casa para a adaptação dos primeiros dias do bebê ou da criança que acaba de chegar. Segundo Razera e Oltramari (2013, p. 45), "sabe-se que sem cuidado prévio a criança não se desenvolve, a inteligência não se estimula e a liberdade não é posta em prática", fatores importantes a serem desenvolvidos para a formação de um adulto sociável.

Não há qualquer dúvida de que a abertura dos legitimados para o requerimento do benefício está ligada aos primeiros cuidados de que se faz necessário a quem chega para compor a família. A evolução legislativa merece aplausos da sociedade, embora decorra da avalanche de concessões judiciais do referido benefício.

Apenas a título de exemplo, pode-se citar a decisão proferida no Recurso Cível $\mathrm{n}^{\circ}$ 5002217-94.2011.404.7016/PR, do Tribunal Regional Federal da $4^{\mathrm{a}}$ Região, julgado em 28/02/2012, por maioria e de relatoria de Guy Vanderley Marcuzzo, cuja Ementa diz que:

Conquanto mencione o art. 71 da Lei 8.213/91 que o salário-maternidade é destinado apenas à segurada, situações excepcionais, como aquela em que o pai, viúvo, é o responsável pelos cuidados com a criança em seus primeiros meses de vida, autorizam a interpretação ampliativa do mencionado dispositivo, a fim de que se conceda também ao pai o salário-maternidade, como forma de cumprir a garantia constitucional de proteção à vida da criança, prevista no art. 227 da Constituição Federal de 1988 (BRASIL, 2012). 
Não há como negar a influência do Poder Judiciário na confecção da lei pelo Legislativo, no entanto, a evolução ainda se mostra insuficiente, se o parâmetro para a equiparação do recebimento do salário-maternidade pelo sobrevivente for a necessidade de cuidados especiais que o bebê ou a criança precisam ao chegar ao novo lar. Reconhece-se o avanço legislativo, no entanto, se analisarmos as estruturas familiares que existem de fato em nossa sociedade, vários bebês e crianças ficariam sem esse amparo.

\section{A CONSTITUIÇÃO E AS NOVAS ESTRUTURAS FAMILIARES}

Como se observou pela análise legislativa, quando do falecimento da segurada ou do segurado que fizer jus ao recebimento do salário-maternidade, a norma ampara o cônjuge ou companheiro sobrevivente, que tenha o filho sob seus cuidados. Contudo, a norma não alcança, por exemplo, a questão da família monoparental: da mãe solteira, cujo filho não foi reconhecido pelo pai, ou que foi abandonada pelo pai da criança; da mãe, cuja gestação é proveniente de inseminação artificial heteróloga ou homóloga post mortem; e nem a situação, citada por Tavares (2008, p. 160), da adoção realizada somente por uma mulher ou por um homem.

Em casos como estes, nos quais não há cônjuge ou companheiro sobrevivente, com o falecimento da segurada ou segurado, os primeiros cuidados com a criança será ficará a cargo de outro parente, que não fará jus ao benefício, nos termos da lei. Logo, a norma apenas alcança as famílias formadas por "pai, mãe e filho(s)", o que se mostra dissociado da nossa realidade, na qual há uma pluralidade de formas familiares.

“A partir da segunda metade do século XX, as instituições familiares ocidentais sofreram transformações de tal monta que os diversos ordenamentos jurídicos tiveram que lidar com as relações familiares de maneira totalmente nova", como observa Moraes e Teixeira (CANOTILHO et.al, 2013, p. 4.994).

À medida que coexistem duas gerações, existe uma família, com a assimetria
correspondente que orienta a obrigatoriedade de transmissão e de produção de
indivíduos no interior de algum tipo de comunidade humana, que se estrutura, a
rigor, tendo duas pessoas como base. Onde há uma mãe e uma criança, um pai e
uma criança, um avô e um neto, um tio que cria um sobrinho, há uma família, com
funções materna e paterna, embora nem sequer sempre desempenhada pelos pais
reais. (RAZERA; OLTRAMARI, 2013, p. 41)

No seu artigo 226, a Constituição Federal de 1988 cuida de, explicitamente, fazer referência a três categorias de família, formadas através do casamento, da união estável e o 
núcleo monoparental. Até então, a ordem jurídica brasileira apenas reconhecia como forma "legítima" de família aquela decorrente do casamento, de maneira que qualquer outro arranjo familiar era considerado marginal. Acompanhando a mudança de valores na sociedade, e o avanço científico das técnicas de reprodução humana assistida, cuidou-se também de imprimir dignidade constitucional aos denominados núcleos monoparentais, formados por qualquer dos pais e sua prole (GAGLIANO, PAMPLONA FILHO, 2014, p. 43-44).

Mas, teria esse sistema constitucional esgotado todas as formas de família? Nesse sentido, concorda-se com o posicionamento de Gagliano e Pamplona Filho (2014, p. 44), quando preconizam que o conceito de família não tem matiz único, porquanto a ordem constitucional vigente consagrou uma estrutura paradigmática aberta, calcada no princípio da afetividade, visando a permitir, ainda que de forma implícita, o reconhecimento de outros ninhos ou arranjos familiares socialmente construídos.

Nesse sentido, Lôbo (2002) ensina:

Os tipos de entidades familiares explicitados nos parágrafos do art. 226 da Constituição são meramente exemplificativos, sem embargo de serem os mais comuns, por isso mesmo merecendo referência expressa. As demais entidades familiares são tipos implícitos incluídos no âmbito de abrangência do conceito amplo e indeterminado de família indicado no caput. Como todo conceito indeterminado, depende de concretização dos tipos, na experiência da vida, conduzindo à tipicidade aberta, dotada de ductilidade e adaptabilidade.

Gagliano e Pamplona Filho (2014, p. 46), nessa toada, procuram estabelecer um conceito moderno de família, como sendo “ [...] o núcleo existencial integrado por pessoas unidas por vínculo socioafetivo, teleologicamente vocacionada a permitir a realização plena dos seus integrantes, segundo o princípio constitucional da dignidade da pessoa humana”.

Percebe-se que o afeto, atualmente, é o principal fundamento das relações familiares (DIAS, 2007, p. 67). "Mesmo não constando a expressão afeto do Texto Maior como sendo um direito fundamental, pode-se afirmar que ele decorre da valorização constante da dignidade humana" (TARTUCE, 2014, p. 43).

Quanto ao conceito de família monoparental, Leite (2003, p. 21) ensina:

Na realidade, a monoparentalidade sempre existiu - assim como o concubinato - se levarmos em consideração a ocorrência de mães solteiras, mulheres e crianças abandonadas. Mas o fenômeno não era percebido como uma categoria específica, o que explica a sua marginalidade no mundo jurídico.

O primeiro país a enfrentar corajosamente a questão foi a Inglaterra (1960), que, impressionada com a pobreza decorrente da ruptura do vínculo matrimonial e com as consequências daí advindas, passou a se referir às one-parent families ou loneparent families, nos seus levantamentos estatísticos.

Dos países anglo-saxões, a expressão ganhou a Europa continental, através da França que, em 1981, empregou o termo, pela primeira vez, em um estudo feito pelo Instituto Nacional de Estatística e de Estudos Econômicos (INSEE). O INSEE francês empregou o termo para distinguir as uniões constituídas por um casal, dos 
lares compostos por um progenitor solteiro, separado, divorciado ou viúvo. Daí, a noção se espalhou por toda a Europa e hoje é conhecida e aceita no mundo ocidental como a comunidade formada por quaisquer dos pais (homem ou mulher) e seus filhos.

As famílias monoparentais, enfoque principal do presente estudo, são constitucionalmente protegidas, como já mencionado, nos termos do artigo $226, \S 4^{\circ}$ da Constituição Federal, e devem ser amparadas pelo Estado diante dos percalços da vida diária. Segundo Nunes (2001, p. 459), “a família monoparental é acolhida pelo ordenamento jurídico, devendo ser afastado qualquer tipo de discriminação em relação a ela e aos seus integrantes".

Segundo o Censo 2011-2012 (IBGE, 2011/2012), num total de 151.800 entrevistados, há 60.548 pessoas casadas, 72.987 solteiros, 9.027 divorciados/separados judicialmente, e 9.239 viúvos, o que demonstra que menos da metade dos entrevistados configuram a família formada por pai, mãe e filhos. O quadro da família brasileira não ficou representando na proteção legal, embora tenha havido evolução legislativa.

Imagine-se a hipótese de uma gestante solteira, que já tem outros dois filhos, que viva numa família formada por ela, seus filhos e sua mãe. No parto a gestante falece e a criança será criada pela avó, empregada doméstica. Em não estando amparada pelo saláriomaternidade da mãe, essa avó terá que pedir demissão do emprego para poder cuidar do recém-nascido. Neste contexto passarão todos, portanto, a viver apenas da pensão por morte deixada pela gestante, pelo menos nos primeiros meses, até a avó colocar o bebê na creche e sair para procurar outro emprego.

No entanto, se essa mesma gestante fosse casada ou vivesse em união estável com o pai da criança, este receberia o salário-maternidade e poderia doar seu tempo integralmente para o desenvolvimento inicial da criança. Neste contexto, a criança receberia os cuidados necessários, sem prejuízo do trabalho de seu pai e do recebimento de uma remuneração.

De fato, há diferença entre as duas situações? O que o salário-maternidade busca proteger não é a criança, nos seus primeiros dias de convívio familiar? Então, qual o motivo da lei ter concedido de forma restritiva o salário-maternidade em caso de falecimento da gestante. Observa-se não haver motivo plausível para justificar tal conduta.

De acordo com Moraes e Teixeira (CANOTILHO et. al., 2013, p. 5.005), o rol do artigo 226 é exemplificativo, "na realidade, existem muitas outras espécies de formações sociais que indiscutivelmente se constituem como entidades familiares, além daquelas indicadas no art. 226 da Constituição", já que na interpretação constitucional da instituição família o elemento "afeto" passou a ser de vital importância para sua caracterização. 
[...] se a família, através da adequada interpretação dos dispositivos constitucionais, passa a ser entendida como instrumental, não há como se recusar tutela a tantas outras formas de vínculos afetivos que, embora não previstas expressamente pelo legislador constituinte, se encontram identificadas com a mesma ratio, com os mesmos fundamentos e com a mesma função. (CANOTILHO et. al., 2013, p. 5005)

Não há motivo legal, justo e moral para que tal artigo não seja interpretado de forma extensiva, abarcando outras figuras familiares que farão às vezes da mãe falecida, independente de ser a avó, a tia, o tio, considerando que a finalidade da lei é a proteção e o cuidado da criança nos primeiros dias de vida ou nos primeiros dias de convívio familiar, em caso de adoção.

[...] o que deve ser entendido pela família é a sua própria função de cuidadora, garantido a suas crianças e seus adolescentes condições dignas de desenvolvimento físico e emocional, permitindo-lhes, de igual modo, o sentimento de fazer parte de uma família, em cujo seio possam vivenciar o afeto, o respeito, a confiança, a cumplicidade, o amor, de forma a desenvolver condições de estabilidade emocional. (RAZERA; OLTRAMARI, 2013, p. 48)

Assim, as novas estruturas familiares devem ser consideradas pelo intérprete da lei, com base na análise da situação de fato, que não pode ficar dissociada da interpretação legal. A análise do caso concreto é de suma importância para a aplicação da lei nos moldes da Constituição Federal e de seu artigo 226, que permite a interpretação ampliativa das estruturas familiares.

\section{O PRINCÍPIO CONSTITUCIONAL DA IGUALDADE}

Estabelece o artigo $5^{\circ}$, caput, da Constituição Federal, "que todos são iguais perante a lei, sem distinção de qualquer natureza", reconhecendo de imediato, a norma constitucional, a igualdade no seu sentido formal, ou seja, a mera igualdade perante a lei. Para Silva (1999, p.217), essa igualdade busca abolir qualquer tipo de privilégio, de regalia infundada, "no sentido de que a lei e sua aplicação tratam a todos igualmente, sem levar em conta distinções de grupos". Pondera Alexy (2012, p. 395) que, nesse aspecto, o dever de igualdade deve ser observado tanto pelos aplicadores do direito, como pelos criadores do direito, dentre eles o legislador.

Desse enfoque conclui-se que a lei deve ser criada para A e para B, e ser aplicada tanto para quando $\mathrm{A}$ ou $\mathrm{B}$ pratiquem a conduta discriminada, independentemente de qualquer característica irrelevante para a subsunção. Portanto, o salário-maternidade foi criado pelo legislador para amparar o trabalho da mãe de baixa renda, da mãe de classe média, e da mãe de classe alta, não havendo motivo plausível para amparar uma e não amparar outra. Não há motivo relevante para que a criança seja cuidada de forma preferencial em seus primeiros dias 
pela mãe de certa classe e não por mãe de outra classe social. A função fundamental do salário-maternidade, como dito, é garantir os primeiros cuidados que a criança precisa, amparando financeiramente o cuidador enquanto afastado de sua atividade laborativa.

Em relação a essa igualdade formal, Alexy (2012, p. 397) observa a seguinte fórmula para a criação da lei: “para todo o $x$, se $x$ tem as propriedades $\mathrm{E}^{1}, \mathrm{E}^{2} \ldots \mathrm{E}$, então, para $x$ deve valer a consequência R". Trata-se de uma igualdade universalizante, que consequentemente admite qualquer forma universalizante de discriminação. Portanto, tal forma não é suficiente.

Essa forma de igualdade estava inserida nas Declarações de Direitos do século XVIII e nas primeiras Constituições, e "exigia um tratamento idêntico para todas as pessoas, submetidas, então, à lei. Essa forma de entender a igualdade não levava a busca da igualdade de condições materiais nem criticava eventuais lacunas da lei” (RAMOS, 2014, p. 474).

No caso em análise, a atitude do legislador no novo diploma legal foi discriminar quem preencha as características estipuladas, fazendo apenas uma análise de direito da situação, se imiscuindo da análise fática da situação. O salário-maternidade será concedido para todo o pai, cônjuge ou companheiro, que ficar com a guarda da criança, olvidando de qualquer outro cuidador que não tenha as características de pai, de cônjuge ou de companheiro.

"Se o enunciado geral de igualdade se limitasse ao postulado de uma práxis decisória universalizante, o legislador poderia, sem violá-lo, realizar qualquer discriminação, desde que sob a forma de uma norma universal, o que é sempre possível” (ALEXY, 2012, p.398).

Segundo Mello (2003, p. 17), a característica discriminadora pode ser escolhida pelo legislador pelo modo que lhe parecer mais compatível com o instituto criado, porém não pode ser deste desarrazoada, sem fundamentado, ou, sequer, incompatível com os ditames constitucionais.

[...] as discriminações são recebidas como compatíveis com a cláusula igualitária apenas e tão-somente quando existe um vínculo de correlação lógica entre a peculiaridade diferencial acolhida por residente no objeto, e a desigualdade de tratamento em função dela conferida, desde que tal correlação não seja incompatível com interesses prestigiados na Constituição. (MELLO, 2003, p. 17)

Para corrigir tal discrepância normativa, a igualdade formal deve ser analisada juntamente com a igualdade material, que leva em consideração a ideia de valoração correta, quando se observa a igualdade valorativa dos indivíduos e a igualdade em relação a determinados tratamentos.

Com o Estado Social de Direito, a igualdade material ou efetiva foi eleita como uma das metas do Estado, com a vinculação da igualdade ao conceito de vida digna. Nesse 
panorama, observamos que a nova normatização do salário-maternidade fere a igualdade na medida em que não permite uma vida digna e a proteção à criança recém-chegada, quando seus primeiros cuidados fiquem a mercê de outra figura familiar que não seja o pai da criança, o cônjuge ou o companheiro(a) da segurada(o) falecido.

Se o objetivo do salário-maternidade é o necessário cuidado que a criança precisa em seus primeiros dias de convívio familiar, a discriminação legal não tem razão de ser, ferindo, portanto, o princípio da igualdade. Segundo Alexy, "uma diferenciação é arbitrária, e, por isso, proibida, se não for possível encontrar um fundamento qualificado para ela" (2012, p.408).

\footnotetext{
A necessidade de se fornecer uma razão suficiente que justifique a admissibilidade de uma diferenciação significa que, se uma tal razão não existe, é obrigatório um tratamento igual. [...].

Não existe uma razão suficiente para a permissibilidade de uma diferenciação quando todas as razões que poderiam ser cogitadas são cogitadas insuficientes. (ALEXY, 2012, p. 408)
}

Se a razão da normatização é a proteção que a criança precisa nos primeiros dias de convivência familiar, na falta da mãe, a lei deve amparar quem ficar responsável por esse cuidado, sob pena de criar uma desigualdade que não coaduna com os objetivos legais. Hoje, como já ficou estabelecido, há na realidade fática formas diversas de estruturas familiares, não havendo razão plausível para a diferenciação trazida pelo diploma legal.

De uma forma direta, com o princípio da igualdade, "o que a ordem jurídica pretende firmar é a impossibilidade de desequiparações fortuitas e injustificadas” (MELLO, 2003, p. 18).

O que se pretende analisar é se o elemento discriminador, cuja adoção exige uma justificativa racional, está em harmonia com o fim constitucionalmente consagrado, devendo o critério utilizado na diferenciação ser objetivo, razoável e proporcional. (NOVELINO, 2008, p. 292)

Como pontua Piovesan (2012, p. 259), há sim uma "exigência contemporânea de igualdade substantiva e real e não meramente formal", o que faz com que a nova normatização deva analisar a situação fática das novas estruturas familiares, estendendo os benefícios ao parente que ficar com a criança sob seus cuidados.

\section{CONCLUSÃO}

Como analisado, a proteção social conferida pelo salário-maternidade é de suma importância para preservar a função fisiológica do processo de criação, facilitar o cuidado dos 
filhos e a atenção à família, garantindo os interesses profissionais da "mãe" (incluídas aqui todas as formas extensivas do benefício) e sua renda no mercado de trabalho.

Não há dúvida de toda a evolução legislativa já alcançada em relação aos sujeitos amparados pelo salário-maternidade, porém, ainda não suficiente para amparar todas as estruturas familiares que vivem concomitantemente em nossa realidade social.

Amparar a mãe gestante, independentemente de sua forma de laboro; amparar a mãe, independente de seu filho ser biológico ou adotivo; amparar a "mãe" quando diante de relações homoafetivas, e amparar o pai, cônjuge ou companheiro, quando do falecimento da segurada ou segurado, demonstra que a finalidade principal do salário-maternidade é suportar os encargos financeiros dessa criação inicial, enquanto a "mãe" está afastada de suas atividades laborativas.

Sendo, portanto, essa a finalidade da proteção legal, não há motivos constitucionais e legais para uma interpretação restritiva do instituto do salário-maternidade no caso de falecimento da segurada ou segurado que fizer jus ao benefício e da consequente mudança da figura que tomará para si esses primeiros cuidados.

Não deve a proteção ficar restrita às situações em que a criança fique aos cuidados do pai, cônjuge ou companheiro (a) da "mãe". No caso da família monoparental, com o falecimento da segurada ou segurado, deve a proteção alcançar qualquer familiar que fique com essa criança sob seus cuidados e que precise, diante disso, se afastar de suas atividades laborativas, devendo quanto a esse ser analisados os requisitos para a possível concessão.

Destarte, observamos que a nova normatização do salário-maternidade, não obstante a reconhecida evolução, viola a igualdade na medida em que não permite uma vida digna e a proteção à criança recém-chegada, quando seus primeiros cuidados fiquem a mercê de outra figura familiar que não seja seu pai, cônjuge ou companheiro de sua mãe. Se o objetivo do salário-maternidade é o necessário cuidado que a criança precisa em seus primeiros dias de convívio familiar, a discriminação legal não tem razão de ser, ferindo, portanto, o princípio da igualdade.

Consequentemente, em relação à família monoparental, havendo o falecimento da segurada ou segurado que fazia jus ao recebimento do benefício, a lei deve amparar quem ficar responsável por esse cuidado inicial com a criança, sob pena de criar uma desigualdade que não coaduna com os objetivos legais.

Hoje, como já ficou estabelecido, há na realidade fática formas diversas de estruturas familiares, não havendo razão plausível para a diferenciação trazida pelo diploma legal. 
Assim, ampliar a proteção estatal à família monoparental coaduna com o Estado Social de Direito, com o princípio da igualdade e com a busca da felicidade, que deve reger a ordem jurídica em sua conjuntura atual.

\section{REFERÊNCIAS BIBLIOGRÁFICAS}

ALEXY, Robert. Teoria dos Direitos Fundamentais. Tradução de Virgílio Afonso da Silva. 2 ed. São Paulo: Malheiros, 2012.

BRASIL. Decreto n ${ }^{\circ} 21.417$, de 17 de maio de 1932. Regula as condições do trabalho da mulher nos estabelecimentos industriais e comerciais. Diário Oficial da União, Rio de Janeiro, DF, Seção 1, 19 maio 1932, p. 9.666. Disponível em: <http://www2.camara.leg.br/legin/fed/decret/1930-1939/decreto-21417-17-maio-1932559563-publicacaooriginal-81852-pe.html>. Acesso em: 02 jul. 2015.

Constituição da República dos Estados Unidos do Brasil, de 16 de julho de 1934.

Diário Oficial da União, Rio de Janeiro, DF, 16 jul. 1934. Disponível em: <http://www.planalto.gov.br/ccivil_03/Constituicao/Constituicao34.htm>. Acesso em: 02 jul. 2015.

Constituição dos Estados Unidos do Brasil, de 10 de novembro de 1937. Diário

Oficial da União, Rio de Janeiro, DF, 10 nov. $1937 . \quad$ Disponível em: http://www.planalto.gov.br/ccivil_03/Constituicao/Constituicao37.htm. Acesso em: 02 jul. 2015.

Decreto 5.452, de $1^{\circ}$ de maio de 1943. Aprova a Consolidação das Leis do Trabalho.

Diário Oficial da União, Rio de Janeiro, DF, 09 ago. 1943. Disponível em: <http://www.planalto.gov.br/ccivil_03/decreto-lei/del5452.htm>. Acesso em: 02 jul. 2015.

Constituição dos Estados Unidos do Brasil, de 18 de setembro de 1946. Diário

Oficial da União, Rio de Janeiro, DF, 19 set. 1946. Disponível em: <http://www.planalto.gov.br/ccivil_03/Constituicao/Constituicao46.htm>. Acesso em: 02 jul. 2015. 
Constituição da República Federativo do Brasil de 1967. Diário Oficial da União,

Brasília, DF, 24 jan. $1967 . \quad$ Disponível em: <http://www.planalto.gov.br/ccivil_03/Constituicao/Constituicao67.htm>. Acesso em: 02 jul. 2015.

Lei 6.136, de 07 de novembro de 1974. Institui o salário-maternidade entre as Prestações da Previdência Social. Diário Oficial da União, Brasília, DF, 08 nov. 1974. Disponível em: <http://www.planalto.gov.br/ccivil_03/leis/1970-1979/L6136.htm>. Acesso em: 02 jul. 2015.

Constituição da República Federativo do Brasil, de 05 de outubro de 1988. Diário Oficial da União, Brasília, DF, 05 out. 1988. Disponível em: <http://www.planalto.gov.br/ccivil_03/constituicao/constituicao.htm>. Acesso em: 02 jul. 2015 .

. Lei 8.213, de 24 de julho de 1991. Dispõe sobre os Planos de Benefícios da Previdência Social e dá outras providências. Diário Oficial da União, Brasília, DF, 25 jul. 1991. Disponível em: <http://www.planalto.gov.br/ccivil_03/leis/18213cons.htm>. Acesso em: 03 jul. 2015.

. Lei n. 8.861, de 25 de março de 1994. Da nova redação aos arts. 387 e 392 da Consolidação das Leis do Trabalho - CLT, altera os arts. 12 e 25 da Lei $n^{\circ} 8.212$, de 24 de julho de 1991, e os arts. 39, 71, 73 e 106 da Lei $n^{\circ}$ 8.213, de 24 de julho de 1991, todos pertinentes à licença - maternidade. Diário Oficial da União, Brasília, DF, 23 mar. 1994. Disponível em: <http://www3.dataprev.gov.br/sislex/paginas/42/1994/8861.htm>. Acesso em: 01 jul. 2015.

Lei n. 9.876, de 26 de novembro de 1999. Dispõe sobre a contribuição previdenciária do contribuinte individual, o cálculo do benefício, altera dispositivos das Leis $\mathrm{n}^{\mathrm{o}} \mathrm{s} 8.212$ e 8.213, ambas de 24 de julho de 1991, e dá outras providências. Diário Oficial da União, Brasília, DF, 06 dez. 1999. Disponível em: <http://www.planalto.gov.br/ccivil_03/Leis/L9876.htm>. Acesso em: 09 jul. 2015. 
Supremo Tribunal Federal. Recurso Extraordinário n. 477554/MG. Rel. Min. Celso de Mello. Informativo do STF, Brasília, DF, n. 635, de 08 a 12 de agosto de 2011. Disponível em: <http://www.stf.jus.br//arquivo/informativo/documento/informativo635.htm>. Acesso em: 27 fev. 2015.

- Tribunal Regional Federal da $4^{\mathrm{a}}$ Região. Recurso Cível $\mathrm{n}^{\mathrm{o}}$ 500221794.2011.404.7016/PR. Consulta Processual Unificada do TRF4, Rel. Guy Vanderley Marcuzzo, julgado em 28 fev. 2012. Disponível em: <http://www2.trf4.jus.br/trf4/controlador.php?acao=consulta_processual_resultado_pesquisa \&txtValor $=50022179420114047016 \&$ selOrigem $=$ PR\&chkMostrarBaixados $=\&$ todasfases $=S$ $\&$ selForma=NU\&todaspartes=\&hdnRefId=27b831e3a646986484bf97bf9ade948c \&txtPalavra Gerada $=$ nnwy\&txtChave=>. Acesso em: 08 ago. 2015.

. Exposição de Motivos da Medida Provisória 619, de 06 de junho de 2013.

Disponível em: $<$ http://www.planalto.gov.br/ccivil_03/_ato20112014/2013/Mpv/mpv619.htm>. Acesso em: 07 jul. 2015.

Medida Provisória 619, de 06 de junho de 2013. Diário Oficial da União, Brasília, DF, 07 jun. 2013. Disponível em: <http://www.planalto.gov.br/ccivil_03/_ato20112014/2013/Mpv/mpv619.htm. Acesso em 27/02/2015>. Acesso em: 07 jul. 2015.

Relatório final para conversão da MP 619/2013 na Lei 12.873/2013. Disponível em: <http://www.camara.gov.br/proposicoesWeb/prop_mostrarintegra;jsessionid=E8A03537F927 063938D1E3893A13F68C.node2? codteor=1142363\&filename=Avulso+-MPV+619/2013 > . Acesso em: 07 jul. 2015.

. Lei 12.873, de 24 de outubro de 2013. Conversão da Medida provisória 619, de 06 de junho de 2013. Diário Oficial da União, Brasília, DF, 25 out. 2013. Disponível em: <http://www.planalto.gov.br/ccivil_03/_ato2011-2014/2013/Lei/L12873.htm>. Acesso em: 25 jul. 2015. Instrução Normativa INSS nº 77, de 21 de janeiro de 2015. Diário Oficial da União,
Brasília,
$\mathrm{DF}$,
22
jan.
2015.
Disponível
em: 
<http://www.normaslegais.com.br/legislacao/Instrucao-normativa-inss-77-2015.htm>. Acesso em: 25 jul. 2015.

CASTRO, Carlos Alberto Pereira de; LAZZARI, João Batista. Manual de Direito Previdenciário. 16 ed. rev. atual. ampl. Rio de Janeiro: Forense, 2014, e-book.

DIAS, Maria Berenice. Manual de Direito das Famílias. 4 ed. São Paulo: Revista dos Tribunais, 2007.

EDUARDO, Ítalo Romano; EDUARDO, Jeane Tavares Aragão. Curso de Direito Previdenciário. Rio de Janeiro: Elsevier, 2013.

GAGlianO, Pablo Stolze; PAMPlOnA FILHO, Rodolfo. Novo Curso de Direito Civil. Direito de Família. As famílias em perspectiva constitucional. 4 ed. rev. atual. São Paulo: Saraiva, 2014, e-book.

INSTITUTO BRASILEIRO DE GEOGRAFIA E ESTATÍSTICA (IBGE). Censo 2011/2012. Disponível em: <http://www.ibge.gov.br/home/estatistica/populacao/trabalhoerendimento/pnad2012/sintese_ defaultxls.shtm>. Acesso em 25 jul. 2015.

LEITE, Eduardo de Oliveira. Famílias Monoparentais. 2. ed., São Paulo: Revista dos Tribunais, 2003.

LÔBO, Paulo Luiz Netto. Entidades Familiares Constitucionalizadas: para além do numerus clausus. Revista Jus Navigandi, Teresina, ano 7, n. 53, jan. 2002. Disponível em: <http://jus.com.br/artigos/2552>. Acesso em: 11 ago. 2015.

MELlo, Celso Antônio Bandeira de. O Conteúdo Jurídico do Princípio da Igualdade. 3 ed., 11 tiragem. São Paulo: Malheiros, 2003.

MORAES, Maria Celina Bodin de; TEIXEIRA, Ana Carolina Brochado. Comentário ao artigo 226. In: CANOTILHO, J.J. Gomes.et al. (Coord.) Comentários à Constituição do Brasil. São Paulo: Saraiva/Almedina, 2013, p. 4994-5023, e-book. 
NOVELINO, Marcelo. Direito Constitucional. 2 ed. São Paulo: Método, 2008.

NUNES, Lydia Neves Bastos Telles. A família - Uma visão constitucional. Revista de Pesquisas e Estudos: divisão jurídica, Bauru, nº 33, dez.2001 a mar. 2002.

PIOVESAN, Flávia. Temas de Direitos Humanos. 5 ed. São Paulo: Saraiva, 2012.

RAMOS, André de Carvalho. Curso de Direitos Humanos. São Paulo: Saraiva, 2014.

RAZERA, Bruna; OLTRAMARI, Fernanda. O afeto e o cuidado nas relações familiares: construindo os alicerces de uma nova casa. Revista Síntese, Direito de Família, São Paulo, no 78, p. 37-51, jun./jul. 2013.

SILVA, José Afonso. Curso de Direito Constitucional Positivo. 16 ed. São Paulo: Malheiros, 1999.

TARTUCE, Flavio. Direito Civil. Direito de Família. 9. ed. rev. atual. e ampl. São Paulo: Método, 2014, v. 5., e-book.

TAVARES, Marcelo Leonardo. Direito Previdenciário. Rio de Janeiro: Lúmen Júris, 2008. 